\title{
Safety and Management of Building Survey Training Room in Higher Vocational Colleges
}

\author{
Zonggui Huang
}

\author{
Department of Architecture and Environment Engineering, Sichuan Vocational and Technical \\ College, Suining, Sichuan 62900, China
}

Keywords: Vocational colleges, architecture, measurement, training room, safety, management

\begin{abstract}
Based on the advancement of the reform of higher education and the development of the new normal economy, cultivating high-quality talents with social and practical applications has become the main task of higher vocational education reform. The key to training students' practical ability lies in constructing a sound training system. The training room is an important part of vocational education. In recent years, with the continuous development of vocational education, the construction of training rooms in higher vocational colleges has achieved great results. In particular, equipment, techniques, and instruments in training rooms have been updated relatively quickly. At the same time, the safety of the training room also attracted the attention of higher vocational colleges. In practice, there are many cases of huge personal and property losses due to the hidden safety problems in the training room.
\end{abstract}

\section{Introduction}

The number of training rooms in higher vocational colleges is large, the number of disciplines involved is large, professionalism is strong, and the requirements for safety management are high. It is the primary goal of safety management in the training room to ensure the safety of teachers and students in training rooms. Relying solely on the functional departments of the school, it is difficult to guarantee the safety of the training room from the aspects of manpower, material resources, and financial resources, and it is also impossible to satisfy the professional knowledge requirements of the safety management of the training room. Even if a large amount of investment is put into the construction of safety facilities and protective equipment in the training room, if there is no strict training room safety operation procedures and awareness of safety responsibilities, it still cannot fundamentally eliminate potential safety hazards.

The focus of safety work in the training room is to prevent accidents. However, the safety management mode of "safety inspection-renovation-re-examination-reorientation" is actually not effective. According to the teaching materials of safety and health education in the training room of the University of Tzu, Taiwan, the proportion of human factors in the training room accidents is as high as $88 \%$. People's safety awareness is an important cause of safety accidents in the training room. This requires the safety management personnel of the training room to change the management concept, strengthen safety education work, and form a management philosophy that safety education is the main responsibility and examination of the training room is supplementary.

Therefore, establish and improve the school-wide standardized, reasonable, and effective safety education model in the training room, and establish the awareness of safety responsibility of the training room managers, staff, teachers, and students. This is of great significance for safeguarding the normal conduct of teaching and research work.

\section{The Proposed Methodology}

Problems in Safety Management of Training Room in Higher Vocational Colleges. Vocational colleges focus on cultivating students' practical abilities, so the training room is an important place for vocational students to acquire practical abilities. Taking the auto professional training room as an 
example, due to the relatively large number of equipment in the training room, students lack the corresponding practical operation skills. Therefore, students have hidden safety problems when they participate in practical training. This requires management personnel to do a good job in safety education, but in practice The teachers and students of higher vocational colleges generally have weak security awareness. On the one hand, higher vocational colleges attach great importance to the introduction of training equipment, such as the regular elimination of outdated training equipment, but on the management of fire equipment. There is a phenomenon of paralysis, such as the problem of fire equipment expired. On the other hand, students' safety awareness is weak, for example, students do not understand basic escape methods when a fire occurs in a training room.

The training room equipment operation has a strict stipulation system, but in higher vocational colleges, the practice of non-standard training is relatively common, especially when the students can not strictly follow the teacher's explanation in the practical training operation, so it is easy to cause security accidents. For example, in the course of automobile training, students' non-standard operations may cause fires, which will cause huge losses to vocational colleges and also threaten students' personal safety.

The safety management system is the basic guarantee for guaranteeing the safe operation of the training room. Higher vocational colleges have established a perfect management system for the training of the training room. However, there is a problem that the establishment and implementation are not in place and implementation is not strict, for example, vocational training Room safety management has established a system of regular inspections. However, in practice, higher vocational colleges tend to formalize safety inspections, leading to the inability to detect hidden safety problems in time. For example, the fire caused by the aging of the circuit is an important form of safety accident in the training room. The aging of the circuit can be completely eliminated through regular inspection.

Strengthen training and safety training in training rooms. Based on the weak security awareness of teachers' survival in higher vocational colleges, higher vocational colleges should strengthen safety education and training to improve teachers and students' awareness of safety precautions. First, safety education should be incorporated into the teaching system of higher vocational education. Safety education is a vocational college. The important curriculum of the school, based on the needs of practical teaching, vocational colleges should integrate the safety education curriculum into the daily teaching activities so that the students can gradually develop the awareness of safety precautions; secondly, higher vocational colleges should regularly carry out safety education and training activities to raise the Vocational colleges and universities staff safety management skills, timely elimination of the existence of hidden safety training room; finally relying on campus activities to carry out safety education and publicity, and create a safe atmosphere of campus culture.

Based on the phenomenon of non-compliance of students in the training room, higher vocational colleges must strengthen the management of students: on the one hand, it is necessary to strengthen the supervision and management of students' practical training operations so that students can acquire the correct training operation skills. For example, before the students enter the training room for training, the teacher must provide targeted education and training to students so that they can understand the process of training. On the other hand, it strengthens students' awareness of safety precautions. For example, vocational colleges focus on the subject of experimental training and safety, and provide special safety education for all new students on how to prevent, how to do, and how to save themselves in daily learning. Students are required to master the safety knowledge and precautions of the experimental training room. Implement the operation flow of equipment and equipment, put the standard operation in front, put safety precautions first, and prevent and eliminate the occurrence of safety accidents in experimental training.

The management system is the key to safety management. Inadequate systems lead to ambiguous management responsibilities. After an accident, they can be evaded from each other. There are some irrational areas in the management system. The training staff is instinctively rejecting the loophole system. It is easy to deny the entire management system because some systems are unreasonable. This creates a slackening mentality, and the management system is virtually useless. In summary, the 
formulation of the management system must be meticulous and precise. Comprehensively consider the various safety issues that may be encountered, starting with each instrument and each person, so that everyone involved is responsible, and there can be only one responsible person. A clear and responsible person is the basis for the reasonable implementation of the reward and punishment system. .

Discussion on Safety Education Mode in Training Room. The safety management of the training room is long-term, systematic, and professional. The fundamental solution to the safe work of the training room is to start with environmental education and safety education, and to raise the awareness of the environment and safety of teachers and students' staff. Standard training room Safe management and practical implementation to ensure personnel safety and property safety in the training room. The safety education in environmental education and training rooms is indispensable. Only by increasing the awareness of environmental protection among teachers and students can we gradually standardize the safety operation procedures in the training room and form a virtuous circle. At present, it is still difficult for higher vocational colleges to take the training of the training room as a compulsory course. How to gradually implement safety education and construct a scientific education system is a problem that must be seriously discussed.

Full process, full staff. In higher vocational colleges, students gradually come into contact with various types of training and participate in the learning and research of training rooms. Therefore, safety training in training rooms is always the entire process of teaching and research activities. At the same time, the personnel entering the training room include teachers, students, other staff in the training room, and sometimes also personnel who participate in training outside the school. They involve a large number of people, and require that all involved personnel receive the necessary training room. safe education.

Multi-level and professional. The training room involves many disciplines, strong professionalism, frequent replacement of training room personnel at different levels, and many innovative and practical trainings with high risks. This also requires that training in the training room be able to face all involved personnel, but also cover the professional training involved.

Diversification of forms. Many training rooms carry forward-looking, pioneering, and diversified exploratory training. The traditional training room safety education courses are often unable to meet. Therefore, it is necessary to combine various types of training and exchanges to enrich, update, and improve. Training room safety education content to adapt to the development of science and technology.

According to the situation of domestic higher vocational colleges, and referring to the safety education and training in the training rooms of higher vocational colleges in Hong Kong, Taiwan and Japan, the safety education in the training rooms of domestic higher vocational colleges can adopt the following methods to gradually form a complete safety education. system.

Higher vocational institutions require students entering the training room to meet the conditions for entry into the training room. According to the characteristics of different disciplines, it is possible to establish an admission standard that is suitable for the school's and scientific training rooms, and gradually promote the access system in all training rooms. This is the basis for carrying out safety education. Only in this way can safety education be implemented scientifically.

The training room safety education class should be a very important course in higher vocational colleges. Cultivating senior personnel with safety awareness is the social requirement for modern higher vocational education. The safety training in the training room should be gradually incorporated into the routine teaching work, and be included in the scope of examinations and examinations to comprehensively improve students' safety knowledge level. The training room staff should earnestly study safety technical knowledge, strengthen safety awareness, improve safety quality, and do a good job in safety management.

First education. The training and safety training courses in the training room are not only compulsory courses for students, but also require teachers and researchers who are new to work. They must also be required to go through strict safety education and training. Students' safety education can be combined with new entry education. New employees can be combined with induction training. 
Universal education. Relying on the establishment of compulsory courses and elective courses for all schools in various departments, students of various science and engineering majors are targeted to conduct safety education before entering the training room.

Professional Education. Relying on various training rooms, according to the practical safety requirements of each training room, the personnel entering the training room shall be provided with targeted safety operation procedures.

Online education. In view of the full-scale and full-staffed character of the safety education in the training room, all of the former methods are used for training. It takes human and material resources and the actual effect is not too good. According to the characteristics of the students' familiarity with the network, they can make full use of the flexibility of the network platform, the richness of knowledge, the diversity of courseware, use advanced culture to guide students, use rich information to attract students, and use comprehensive knowledge to serve students. Students can choose their own time, but each school year must pass the study and exam of the cybersecurity education platform. This method is used as an auxiliary means to run through all students in school.

\section{Conclusion}

Safety is the foundation for people to pursue all good life goals. It is the cornerstone of innovation and development. Safety training in training rooms is an effective means and long-term mechanism to ensure the safety management of training rooms in higher vocational colleges. It ensures the normal operation of teaching and scientific research. The important part of it is also a long-term and advancing work. It is necessary to fully understand the new characteristics of the security work in the training room of higher vocational colleges, establish and improve the safety training system for the training room, establish the safety awareness of the teachers and students, and cultivate the safety operation and emergency response capabilities of teachers and students. This is high. The important component of safety culture education in vocational schools is also the fundamental to prevent accidents in training and reduce accident damage. Only teachers and students with a good safety culture can create a safe and harmonious teaching and research environment.

\section{Acknowledgement}

The support of this research by the Sichuan Science and Technology Project (No. 2015GZ0343)

\section{References}

1. Graziano, L. M., Rosenbaum, D. P., \& Schuck, A. M. (2014). Building group capacity for problem solving and police-community partnerships through survey feedback and training: a randomized control trial within chicago's community policing program. Journal of Experimental Criminology, 10(1), 79-103.

2. Perrymanning, S. (2007). Naccrra's national survey of child care resource \& referral training: building a system for the child care workforce [executive summary].

3. Holmes, B. J., Schellenberg, M., Schell, K., \& Scarrow, G. (2014). How funding agencies can support research use in healthcare: an online province-wide survey to determine knowledge translation training needs. Implementation Science, 9(1), 1-10.

4. Wang, J., Wang, H., Zhou, Y., \& Mcdonald, N. (2016). Multiple Kernel Multivariate Performance Learning Using Cutting Plane Algorithm. IEEE International Conference on Systems, Man, and Cybernetics (pp.1870-1875). IEEE.

5. Bloomfield, G. S., Xavier, D., Belis, D., Alam, D., Davis, P., \& Dorairaj, P., et al. (2016). Training and capacity building in lmic for research in heart and lung diseases: the nhlbi-unitedhealth global health centers of excellence program. Glob Heart, 11(1), 17-25. 